It was decided to try the effects of immunosuppressant therapy in this case since there were certain features similar to those of massive pulmonary fibrosis and a possibility that a delayed immune response might account in part for the lung damage. He was started on azathioprine $50 \mathrm{mg}$ four times daily and in addition was given four times daily and in addition was given potassium aminobenzoate as an antifibrotic measure. The effect of the immunosuppressant therapy was monitored by frequent blood counts and immunophoresis of gammaglobulins. The started, the IgG level being reduced to $5 \cdot 83 \mathrm{~g} / 1$ started, the IgG
$(583 \mathrm{mg} / 100 \mathrm{ml})$.

On 23 December the lung appearances began to improve, starting on the right side and to a lesser extent the left, and on 30 December there was further resolution of the lesions. Concomitantly with this his blood urea level began to fall and reached $10.3 \mathrm{mmol} / 1(62 \mathrm{mg} / 100 \mathrm{ml})$, the creatinine reached $10.3 \mathrm{mmol} / 1(62 \mathrm{mg} / 100 \mathrm{ml})$, the creatinine level being $61.9 \mu \mathrm{mol} / 1$ being $(0.7 \mathrm{mg} / 100 \mathrm{ml})$, and $\mathrm{Po}_{2}$ steadily rose. These changes were all associated with a progressive clinical improvement which has
been maintained, though his lung changes have been maintained, though his
not yet completely resolved.

I hope to publish further details concerning this patient at a later date but feel that while this isolated case may "prove nothing," in view of the usually grave prognosis associated with severe paraquat poisoning, especially when associated with marked pulmonary radiological signs, this patient's response may be of interest to clinicians who may be dealing with such cases, particularly late cases in which the use of adsorption agents such as Fuller's earth and haemodialysis are not applicable.-I am, etc.,

JAMES A. LAITHWAITE

Law Hospital,
Carluke, Lanarkshire

\section{Septicaemia on the Increase}

SIR,-Your leading article on septicaemia (14 December, p. 615) reminds us that "the intravenous tubes now so commonly used are a convenient portal of entry for these infections." One way in which suoh infection can enter is by accidental contamination of the piercing needle of the giving se when it is removed from an empty bottle and inserted into a full one. This change over is made some 1300 times each week in the surgical wards in Abendeen hospitals. Therefore the procedure should be as simple and safe as possible.

Currently we use Avon 11 giving sets, as we have done for 16 years since a Medica Research Council subcommittee ${ }^{1}$ devised and recommended them, and they have proved highly satisfactory. They have a combined air-inlet and piercing needle, a good grip can be obtained on the rigid filter chamber, a flange prevents the operator's fingers touching the needle which pierces the bung, and nurses find them easy and quick to manipulate. It is therefore surprising to find that official recognition has been withdrawn from this set. There are now only two giving sets listed in the D.H.S.S. schedule of medical and surgical equipment (13 May 1974, p. 1408)-the Avon A 15 and the Travenot F.K.C. 2005. Both have been designed for use with plastic bags containing stored blood and other derivatives and are excellent for this purpose. Because a plastic bag collapses as it empties there is no need to incorporate an air-inlet into these sets. When, however, these sets are used to give fluids supplied in glass bottles a separate air-inlet assembly must be inserted through the bung in order to admit air while fluid leaves the rigid bottle.
The A 11 set seems to have been withdrawn because blood and its byproducts will soon be generally distributed in plastic bags, and it is not safe to penetrate a plastic bag with the piercing
needle of the A 11 set. No one disagrees that the A 15 set is essential here. However, our pharmaceutical colleagues expect intravenous electrolyte and dextrose solutions, dextran, amino-acid solutions, and fat emulsions to be supplied in glass (o be supplied in glass bottles for some years to come. In Aberdeen during 1974 the pharmacy has manufactured infusion fluids in $135000500-\mathrm{ml}$ glass bottles and half paediatric surgical wards. The transfusion of blood is largely confined to the day of operation, and many patients do not require any blood. On the other hand, most patients who undergo major alimentary-tract surgery or who come in with peritonitis or intestinal obstruction cannot drink for some days. During this time they receive solutions of sodium, potassium, and dextrose, and in my adult ward it is usual to have about eight patients on this treatment at one time. If we have to use the two official sets for all these infusions then every time a bottle is changed two needles must be changed instead of one on some 1300 must be changed instead of one on some 1300 occasions each week. Not only is this unnecessary
work but there is a serious additional risk of work but there is a serious additional risk of contamination, because the separate air-inlet
needles supplied are difficult to hold and to introduce through the thick bungs of the bottles. introduce through the thick bungs of the bottles.
The likelihood of a nurse's fingers contaminating The likelihood of a nurse's fingers
the lower end of this needle is high.

This risk is unacceptable in any patient but it is especially dangerous practice among patients on long-term intravenous feeding. The great care taken over the insertion of the necessary central taken over the insertion of the necessary central
venous catheters and over their maintenance over venous catheters and over their maintenance over
days and weeks can be frustrated by the use of days and weeks can be frustrated by the use of giving sets never designed tc be used with glass
bottles. It is no argument to claim that these sets bottles. It is no argument to claim that these sets knows that intravenous lines can become infected and how serious this is; can we exclude faulty technique of needle insertion into solution bottles as one source of infection? Happily we can still purchase $A 11$ sets and avoid this risk, but for how long will manufacturers continue to make a se which is not officially recognized ?

The D.H.S.S. appears to have restricted recognition of the A 15 and F.K.C. 2005 sets on the grounds that it is more economical and less confusing to have only one type of giving set available which will safely enter a bag of blood. This is understandable, but in fact we have to keep both the $A 11$ and $A 15$ sets at present, because blood sometimes arrives in bags, and no confusion arises. The major fact which has been overlooked is the very large amount of electrolyte and dextrose solutions used on medical wards, all of which are supplied in glass bottles. I and many of my nursing and surgical colleagues believe that there is an overwhelming case for allowing the A 11 to join the A 15 as an officially recognized giving set.-I am, etc.

PETER F. JONES

Royal Aberdeen Children's Hospital,

Aberdeen

1 Medical Research Council Blood Transfusion Research Committee, Lancet, 1957, 1, 595.

Ischaemic Heart Disease in Young Women

SIR,-Though the gives no figures of his own, Dr. I. McD. G. Stewart (14 December, p. 653) doubts the validity of my assessment (2 November, p. 253) of the prevalence (34\%) of hypertension in women who developed ischaemic heart disease under the age of 45, and some clarification appears necessary.

(1) All women classified as having hypertension were recorded by me as having a diastolic blood pressure of $100 \mathrm{~mm} \mathrm{Hg}$ or more and the lowest reading of three taken over a period of 10 minutes was used for this criterion. Of 50 women so classified, 43 (28 out of 32 with myocardial infarction) had a diastolic blood pressure of $100 \mathrm{~mm} \mathrm{Hg}$ or more recorded on three or more separate clinical examinations. None were regarded as hypertensive solely on the basis of treatment "at the hands of their family doctor."

(2) In $23 \%$ the electrocandiogram showed left ventricular hypertrophy. This was defined in the customary way as $R_{a V L}>11$ $\mathrm{mm}$ or $\mathbf{R}_{\mathrm{aVF}}>20 \mathrm{~mm}$ and $\mathrm{S}_{\mathrm{V}_{1}}+\mathbf{R}_{\mathrm{V}_{6}} \geqslant 35$ $\mathrm{mm}$ : obviously, $S-T$ and $T$-wave $a b$ normalities would be of little value in the assessment of left ventricular hypertrophy in patients with previous myocardial infarction.

(3) The prevalence of diastolic hypertension $(28 \%)$ or of left ventricular hypertrophy in those presenting with angina was only slightly, and not significantly, less than that in those with myocardial infarction. This supports the view that hypertension is an important pre-infarction risk factor in young women.

(4) While a prospective study would probably give more reliable data about the prevalence of each risk factor, Dr. Stewart should consider the magnitude of implementing such a study in women of this age group, in which the incidence of myocardial infarction is so small, and ask himself why no comparable data are available even from the Framingham survey or from the InterSociety Commission for Heart Disease Resources (Pooling Project)-two of the largest prospective surveys of risk factors in relation to ischaemic heart disease.

(5) The majority of women with diastolic hypertension also smoked cigarettes or had hyperlipidaemia. Thus hypertension should not be regarded as the only risk factor contributing to the early development of myocardial infarction.

At present there are no alternative data from which to deduce the prevalence of diastolic hypertension in young women with ischaemic heart disease, and $28-40 \%$ (mean $34 \%$ ) is as near as we can get.

Finally, it was certainly no surprise to me to find that coexisting hypertension worsened the prognosis in each group. This correspondence may help to emphasize the need for assiduous control of diastolic hypertension in young women.-I am, etc.,

M. F. OLIVER

Department of Cardiology,
Royal Infirmary, Edinburgh

Tuberculosis of the Spine

SIR,-In your leading article under the above heading (14 December, p. 613) you refer to our work in Nigeria and state that we treated our ambulant patients with "chemotherapy alone, using neither rest, nor splintage, nor operations."

In fact our paper ${ }^{1}$ reporting the management of patients suffering from spinal tuberculosis certainly mentioned surgery, albeit of a simple nature. Perispinal abscesses were drained when they were associated with paraplegia and the patient was unable to walk (that is, could not yet undergo ambulant treatment). Believing that the paraplegia is primarily caused by the pressure of the abscess on the cord we contented ourselves with the removal of the inner end of a rib or ribs and emptying the abscess under direct vision (costectomy). Twentyseven out of a total of 207 patients wer 